\title{
Pesquisa de Salmonella spp. em galinhas criadas em fundo de quintal (Gallus gallus domesticus) e ovos comercializados nas feiras livres na cidade de Fortaleza, Ceará
}

\author{
Investigation of Salmonella spp. in backyard chickens \\ (Gallus gallus domesticus) and eggs sold in free markets in \\ the city of Fortaleza, Ceará
}

\author{
Valdez Juval Rocha Gomes Filho'; Régis Siqueira de Castro Teixeira²; \\ Elisângela de Souza Lopes ${ }^{3}$; Átilla Holanda de Albuquerque ${ }^{3}$; \\ Suzan Vitória Girão Lima ${ }^{4}$; Ruben Vasconcelos Horn ${ }^{3}$; \\ Roberta Cristina da Rocha-e-Silva ${ }^{5}$; William Maciel Cardoso ${ }^{6 *}$
}

\begin{abstract}
Resumo
A carne de aves e seus subprodutos são as principais fontes de proteína para o homem. No entanto estão implicadas em surtos de toxi-infecção em todo o mundo, causada principalmente por Salmonella spp. Assim, o presente trabalho teve como objetivo investigar a presença de Salmonella spp. em material coletado em propriedades criadoras de galinhas de fundo de quintal (ovos, ração, swab cloacal e de arrasto) e realizar um levantamento das enterobactérias encontradas nos ovos comercializados nas principais feiras livres da cidade de Fortaleza. Foi realizado coleta de $s w a b$ cloacal individual em 405 galinhas caipiras de 18 criatórios, e coletado dez ovos por propriedade para análise do conteúdo interno e da casca, totalizando 180 ovos. Amostras de swabs de arrastos e de ração também foram coletadas nas propriedades. Nas feiras livres, foram adquiridos 90 ovos. Após coletados, a ração, os swabs cloacais e de arrasto, casca e conteúdos interno dos ovos foram colocados em Água Peptonada (AP) e em seguida transferido uma alíquota para caldo Rappaport-Vassiliadis (RV) e Seletino-Cistina contendo novobiocina (SCN). Seguidamente foi realizado plaqueamento em Ágar Verde Brilhante (AVB) e MacConkey (MC). As colônias suspeitas para Salmonella spp. foram submetidas à identificação bioquímica, sendo a temperatura e período de incubação padronizado em todas as etapas em $37^{\circ} \mathrm{C} / 24 \mathrm{~h}$, respectivamente. Os ovos das feiras passaram por testes bioquímicos adicionais para identificação de outras enterobactérias. Não houve isolamento de Salmonella spp. em nenhuma das amostras de swabs e ovos. Contudo, foi possível isolar Escherichia coli, Citrobacter spp., Enterobacter spp., Proteus spp., Providencia spp., Klebsiella spp., Shigella spp., Yersinia spp. dos ovos das feiras livres. De acordo com a metodologia utilizada, podemos sugerir que galinhas de fundo de quintal de Fortaleza possui o status sanitário satisfatório. Por outro lado, os ovos de feiras livres não apresentam boas condições higiênico-sanitárias.

Palavras-chave: Swab cloacal, Salmonella spp, galinhas de fundo de quintal, enterobactérias, ovos
\end{abstract}

\footnotetext{
${ }^{1}$ M.e em Ciências Veterinárias, Programa de Pós graduação em Ciências Veterinárias, Universidade Estadual do Ceará, UECE, Fortaleza, CE. E-mail: valdezbio@yahoo.com.br

${ }^{2}$ Bolsista de Pós doutorado, CNPq, Universidade Estadual do Ceará, Fortaleza, CE. E-mail: regis_siqueira_teixeira@yahoo.com. br

${ }^{3}$ Discentes de Doutorado do Programa de Pós-Graduação em Ciências Veterinárias, UECE, Fortaleza, CE. E-mail: elisangeladesouzalopes@hotmail.com; atillaholanda@hotmail.com; rubenhorn@hotmail.com

${ }^{4}$ Bolsista de Iniciação Científica, FUNCAP, UECE, Faculdade de Veterinária, Fortaleza, CE. E-mail: xxsuper_suzanxx@hotmail. com

${ }^{5}$ Dra $^{\mathrm{a}}$ em Ciências Veterinárias, Programa de Pós-graduação em Ciências Veterinárias, UECE, Fortaleza, CE. E-mail: robertarochavet@hotmail.com

${ }^{6}$ Prof. Dr. Adjunto, UECE, Fortaleza, CE. E-mail: E-mail: william.maciel@uol.com.br

* Autor para correspondência
} 


\begin{abstract}
Poultry meat and byproducts are the main protein source for man. However, such foods are related to outbreaks of food-borne infections around the world, caused mainly by Salmonella spp. Therefore, the present study aimed to investigate the presence of Salmonella spp. in material collected in properties of backyard chickens (eggs, ration, cloacal swab and drag swab) and to perform a survey of members of the Enterobacteriaceae family in eggs commercialized in the main free markets of Fortaleza. Individual cloacal swabs were collected from 405 backyard chickens from 18 houses and 10 eggs were also collected for analysis of eggshell and internal content from each sampled household, totaling 180 eggs. From the free markets, 90 eggs were collected. Once sampled, the ration, cloacal swab, drag swab, shell and internal contents of eggs were incubated in Peptone Water and aliquots were placed in RappaportVassiliadis broth and Selenite-Cystine broth added Novobiocin. Following, aliquots of each broth were streaked in plates Brilliant Green agar and MacConkey agar. Suspect colonies for Salmonella spp. were submitted to biochemical identification, with the temperature and incubation time standardized in $37^{\circ} \mathrm{C} / 24 \mathrm{~h}$, respectively. Eggs collected from houses were broken in sterile beaker and maintained in bacteriological incubator at $37^{\circ} \mathrm{c} / 24 \mathrm{~h}$. After such period, aliquots collected were incubated in RappaportVassiliadis broth and Selenite-Cystine broth added Novobiocin, following the same bacteriological procedure mentioned previously for swabs. Eggs from free markets were analyzed with the same methodology as the house eggs, minus the antibiotic Novobiocin in the Selenite-Cystin broth, and with further biochemical tests used to identify the different members of the Enterobacteriaceae family. No Salmonella spp. were isolated from swab or egg samples. However, Escherichia coli, Citrobacter spp., Enterobacter spp., Proteus spp., Providencia spp., Klebsiella spp., Shigella spp., Yersinia spp. were isolated from eggs of free markets. Accordingly to the methodology used, we may suggest that backyard chickens from Fortaleza present a satisfactory sanitary status. However, free market eggs did not present adequate sanitary conditions.
\end{abstract}

Key words: Cloacal swab, Salmonella spp, backyard chickens, enterobacteriaceae, eggs

\section{Introdução}

A salmonelose, doença causada por bactérias do gênero Salmonella, é uma das zoonoses que trazem transtorno a saúde pública mundial devido à capacidade de causar toxi-infecção alimentar (WHITE et al., 1997), podendo levar o indivíduo ao óbito. Esta infecção está associada ao consumo de carne de aves e de produtos avícolas contaminados com sorotipos paratifoides de Salmonella spp. (LOURENÇO; REIS; VALLS, 2004; WHITE et al., 1997).

Apesar de todo o desenvolvimento tecnológico na produção de alimentos e da adoção de melhores medidas higiênicas e sanitárias (GAST; SHIVAPRASAD; BARROW, 2008), as aves ou o produto final pode se contaminar com Salmonella spp. através de aves de reposição, incubatório, animais silvestres e domésticos, falhas na biossegurança e no manejo, alimento contaminado e na linha de abate (CARDOSO; TESSARI, 2008; FREITAS NETO et al., 2010).
$\mathrm{Na}$ criação intensiva em larga escala, microorganismos como Salmonella spp., uma vez que são introduzidos nas granjas, podem facilmente se propagar. Por não possuírem hospedeiros específicos, torna-se difícil a erradicação deste patógeno do ambiente de criação ou eliminá-los dos produtos provenientes de animais contaminados (CARDOSO; TESSARI, 2008; FREITAS NETO et al., 2010).

Existe outro tipo de criação que são as galinhas popularmente conhecidas como "galinhas caipiras". De acordo com Silva (2005), a criação de galinha caipira pode ser dividida em duas categorias: a primeira são as criações em fundos de quintal, originando produtos caipiras, enquanto a segunda categoria é constituída por galinha caipira industrial ou frango de corte que são criados no sistema semi-intensivo ou no sistema caipira de criação, não se tratando de uma criação completamente desorganizada. A principal diferença entre as duas criações se dá em relação ao melhoramento 
genético que irá influenciar na produtividade, sendo o segundo tipo mais rentável.

No Brasil foram registrado surtos de toxiinfecção alimentar por bactéria do gênero Salmonella sp. causados por alimentos elaborados à base de ovos por bactérias do gênero Salmonella, evidenciando o risco potencial que esse alimento pode representar para a saúde pública (ALCOCER, 2004). Portanto, o objetivo deste trabalho foi investigar, em galinhas de fundo de quintal (GFQ), a presença de Salmonella spp. por teste sorológico e analisar, por método microbiológico, ovos e swabs cloacais, assim como o piso do alojamento destas aves criadas em propriedades localizadas na cidade Fortaleza. Intentou-se, também nesta pesquisa, realizar um levantamento de enterobactérias presentes na casca e no conteúdo interno dos ovos expostos a venda em feiras livres.

\section{Material e Métodos}

\section{Amostragem}

Para as análises realizadas nesta pesquisa, utilizou-se materiais coletados em propriedades criadoras de GFQ (sangue, swab cloacal, ovos e swab de arrasto) e ovos de feiras livres, ambos da cidade de Fortaleza, Ceará.

Fortaleza localiza-se ao norte do Estado do Ceará ( $\left.3^{\circ}, 44^{\prime}-6^{\circ} 01^{\prime} / 38^{\circ}, 23^{\prime}-38^{\circ}, 57^{\prime}\right)$, no território brasileiro, possui $313,140 \mathrm{~km}^{2}$ de extensão territorial e está dividida em seis regionais (figura 1). $\mathrm{O}$ índice pluviométrico varia entre $1.111-1.532 \mathrm{~mm}$ durante todo o ano e a altitude não ultrapassa 14,23-68 m (acima do nível do mar) (BRASIL, 2005).

Para o cálculo do número de galinhas a serem utilizadas, foram considerados os seguintes parâmetros: (a) prevalência esperada; (b) erro absoluto e (c) nível de confiança. O cálculo foi feito com a fórmula para amostras simples aleatórias, conforme proposto por Thrusfield (2004).
Figura 1. Regionais de Fortaleza (CE)

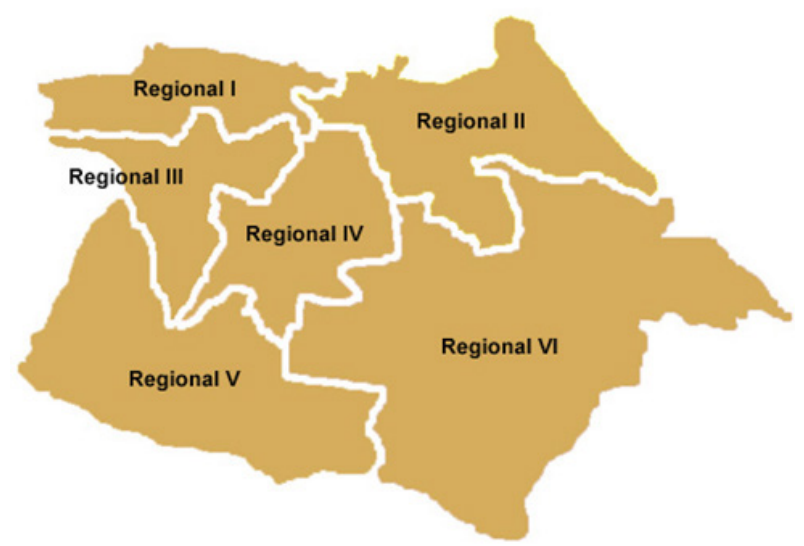

Fonte: Prefeitura Municipal de Fortaleza (2012).

As coletas foram realizadas entre o período de junho de 2012 à janeiro de 2013 em 18 criatórios, distribuídos nas regionais da cidade (três criatórios/ regional). Foram coletados um total de 405 swabs cloacais individuais das galinhas (Gallus gallus domesticus) de acordo com Brasil (1995). As aves tinham idade superior a oito semanas e eram submetidas a sistemas de criação extensivos ou semi-intensivos. Durante a visita às propriedades, foi realizado um questionário de múltipla escolha a fim de avaliar o perfil sanitário das criações.

Inicialmente foi realizado teste de soroaglutinação rápida em placa (SAR) em todas as aves, utilizando o teste comercial Pulor teste ${ }^{\circledR}$ (Laboratório Biovet, Brasil), e seguidamente foram coletadas amostras de swabs cloacais. Em cada propriedade visitada foi realizado um swab de arrasto em cinco pontos distintos do ambiente onde as galinhas transitavam ou ficavam a maior parte do tempo (ninho, piso próximo a comedouro, piso próximo ao bebedouro, poleiro, pinteiro). Também foi analisada uma amostra de ração de cada propriedade coletada diretamente de um dos comedouros. Quando a propriedade não possuía um local específico para ração à coleta foi realizada diretamente do chão. As amostras foram conservadas em isopor contendo gelo reciclável e encaminhadas ao Laboratório de Estudos Ornitológicos (LABEO) para processamento microbiológico. Em cada 
propriedade foram adquiridos dez ovos, somando um total de 180 unidades, com a finalidade da detecção de Salmonella sp.

Entre fevereiro e março de 2013, foram adquiridos 15 ovos de galinha de fundo de quintal disponível a venda em uma feira livre de cada regional existente na cidade de Fortaleza. Todos os ovos adquiridos (90 unidades) foram encaminhados ao LABEO e imediatamente submetidos ao processamento microbiológico.

\section{Exame microbiológico}

Aprimeira etapa do procedimento microbiológico consistiu na fase de pré-enriquecimento. As amostras de ração (1g), swab cloacal e de arrasto foram incubadas em $10 \mathrm{~mL}$ de água peptonada tamponada (APT) a $0,1 \%$ por $24 \mathrm{~h}$ a $37^{\circ} \mathrm{C}$. A cada cinco ovos obtidos nas propriedades se obtinham um pool do conteúdo interno e um pool das cascas, o que representou uma soma de 72 amostras. Dos ovos obtidos nas feiras livres, o pool foi realizado a partir de três ovos, totalizando 30 amostras de cascas e 30 amostras de conteúdo. O processo de pré-enriquecimento desse material ocorreu após a quebra asséptica dos ovos, sendo a casca separada do conteúdo interno. Para cada amostra de casca (25g) utilizou-se $225 \mathrm{~mL}$ de APT. O conteúdo dos ovos foi incubado por $24 \mathrm{~h}$ a $37^{\circ} \mathrm{C}$ de acordo com Wigley et al. (2001).

Após a etapa de pré-enriquecimento, foi transferido $1 \mathrm{~mL}$ e $0,1 \mathrm{~mL}$ de cada amostra para os caldos Selenito Cistina contendo novobiocina (SCN) $(0,04 \mathrm{~g} / 1 \mathrm{~L})$ e Rappaport Vassiliadis (RV), respectivamente. Em seguida, alíquotas foram semeadas em placas contendo ágar Verde Brilhante (AVB) e MacConkey (MC), e após incubação a $37^{\circ} \mathrm{C}$ durante $24 \mathrm{~h}$ foram selecionadas colônias sugestivas para Salmonella spp. para a realização das provas de triagem com Ágar Tríplice Açúcar Ferro (TSI), Ágar Lisina Ferro (LIA) e Sulfeto Indol Motilidade (SIM). Como em ovos coletados em feiras livres objetivou-se identificar outras enterobactérias, na etapa de enriquecimento seletivo não foi utilizado novobiocina no caldo Selenito-Cistina. Para esse caso, um procedimento adicional foi a utilização de provas bioquímicas complementares: arginina, ornitina, fenilalanina, vermelho de metila (VM), voges-Proskauer (VP), citrato de Simmons, malonato, ureia, inositol, sorbitol, manitol, rafinose, arabinose, adonitol, ramnose e dulcitol de acordo com Quinn, Cartier e Markey (1994).

\section{Resultados}

Pesquisa de Salmonella spp. em propriedades

A prevalência de positividade para Salmonella spp. a partir do exame SAR de sangue de GFQ foi de $27,1 \%$ (tabela 1 ). A regional $\mathrm{V}$ foi o local onde foi registrado o maior percentual de aves positivas no exame de SAR $(52,8 \%)$, enquanto que a regional I apresentou a menor taxa $(10,2 \%)$. As regionais II, III, IV e VI apresentaram respectivamente os seguintes percentuais de positividade: 36,3\%; $15,3 \% ; 25,7 \%$ e $22,8 \%$.

Apesar do exame de SAR apresentar positividade para Salmonella spp., o exame microbiológico não identificou nenhuma amostra positiva nas amostras de swabs cloacais e conteúdos internos ou cascas de ovos.

A tabela 2 informa o perfil sanitário das propriedades criadoras de galinhas de fundo de quintal na cidade de Fortaleza-CE.

A pesquisa revelou que o tipo de criação mais utilizado foi o semi-intensivo $(61,1 \%)$, seguido da extensiva $(38,8 \%)$ e intensivo (5,5\%). A maioria dos proprietários $(61,0 \%)$ criavam galinhas com finalidade de consumo próprio da carne e ovos, sendo a comercialização das aves e subprodutos o interesse de $44,4 \%$ dos entrevistados. Os demais criadores $(16,8 \%)$ criavam as aves apenas como lazer.

$\mathrm{Na}$ abordagem relacionada às questões sanitárias registrou-se que a troca de água dos bebedouros do recinto de criação das galinhas era realizada diariamente na maioria das propriedades $(77,7 \%)$, 
embora algumas propriedades realizassem a limpeza duas vezes $(16,6 \%)$ ou três vezes por semana (5,7\%). A alimentação das aves era constituída de restos de comida juntamente com milho ou ração comercial $(66,7 \%)$, apenas milho $(22,2 \%)$ ou restos de comidas $(11,1 \%)$.

Tabela 1. Prevalência de galinhas de fundo de quintal positivas no teste de soroaglutinação rápida com antígeno "K" colorido para o diagnóstico de pulorose e tifo aviário.

\begin{tabular}{|c|c|c|c|}
\hline Regional & Propriedade & Aves $(\mathrm{N})$ & $\mathrm{n}^{\circ}$ de aves positivas $-(\%)$ \\
\hline \multirow{4}{*}{ I } & 1 & 15 & $0-(0,0)$ \\
\hline & 2 & 20 & $3-(15,0)$ \\
\hline & 3 & 33 & $4-(12,1)$ \\
\hline & Total & 68 & $7-(27,12 \%)$ \\
\hline \multirow{4}{*}{ II } & 1 & 21 & $4-(19,1)$ \\
\hline & 2 & 23 & $2-(8,7)$ \\
\hline & 3 & 22 & $18-(81,8)$ \\
\hline & Total & 66 & $24-(36,4)$ \\
\hline \multirow{4}{*}{ III } & 1 & 22 & $6-(27,3)$ \\
\hline & 2 & 19 & $1-(5,3)$ \\
\hline & 3 & 24 & $3-(12,5)$ \\
\hline & Total & 65 & $10-(13,4)$ \\
\hline \multirow{4}{*}{ IV } & 1 & 20 & $8-(40,0)$ \\
\hline & 2 & 16 & $7-(43,8)$ \\
\hline & 3 & 30 & $2-(6,8)$ \\
\hline & Total & 66 & $17-(25,8)$ \\
\hline \multirow{4}{*}{ V } & 1 & 20 & 8- $(40,0)$ \\
\hline & 2 & 24 & $20-(83,3)$ \\
\hline & 3 & 26 & $9-(34,6)$ \\
\hline & Total & 70 & $37-(52,9)$ \\
\hline \multirow{4}{*}{ VI } & 1 & 25 & $3-(12,0)$ \\
\hline & 2 & 30 & $6-(20,0)$ \\
\hline & 3 & 15 & $7-(46,7)$ \\
\hline & Total & 70 & $16-(22,8)$ \\
\hline Total & & 405 & $111-(27,4)$ \\
\hline
\end{tabular}

Fonte: Elaboração dos autores.

Os criadores relataram que o contato das galinhas com aves silvestres ocorriam principalmente durante a oferta de alimentação ou água. A maioria dos proprietários (72,2\%) afirmaram que as galinhas tinham algum tipo de contato com passeriformes, pombos, rolinhas ou corujas.
A maioria das propriedades $(88,8 \%)$ nunca utilizou nenhum tipo de antimicrobiano ou programa de vacinação e também nunca foram assistidos por médicos veterinários. Um menor número de propriedades $(11,1 \%)$ utilizavam vacinas e a possuíam assistência de médicos veterinários. 
Tabela 2. Perfil sanitário das propriedades criadoras de galinhas de fundo de quintal criadas na cidade de FortalezaCE.

\begin{tabular}{|c|c|c|c|}
\hline Variável & & $\mathrm{n} / \mathrm{N}$ & Frequência (\%) \\
\hline \multirow{2}{*}{ Aves por propriedade } & Até 25 aves & $9 / 18$ & 50,0 \\
\hline & De 25 a 100 aves & $9 / 18$ & 50,0 \\
\hline \multirow{3}{*}{ Sistema de criação } & Extensivo & $7 / 18$ & 38,8 \\
\hline & Semi-intensivo & $10 / 18$ & 61,1 \\
\hline & Intensivo & $1 / 18$ & 5,5 \\
\hline \multirow{3}{*}{$\begin{array}{l}\text { Troca de água /Limpeza dos } \\
\text { Bebedouros }\end{array}$} & Diariamente & $14 / 18$ & 77,7 \\
\hline & Duas vezes por semana & $3 / 18$ & 16,6 \\
\hline & Três vezes por semana & $1 / 18$ & 5,7 \\
\hline \multirow[t]{2}{*}{ Utilização das vacinas* } & Nunca utilizou & $16 / 18$ & 88,8 \\
\hline & Utilizou & $2 / 18$ & 1,1 \\
\hline \multirow[t]{2}{*}{ Utilização de antibióticos** } & $\operatorname{Sim}$ & $15 / 18$ & 83,3 \\
\hline & Não & $3 / 18$ & 16,6 \\
\hline \multirow[t]{2}{*}{ Finalidade da criação } & Consumo & $7 / 18$ & 38,8 \\
\hline & Comércio & $4 / 18$ & 22,2 \\
\hline \multirow{6}{*}{ Alimentação ofertada } & Consumo e comércio & $4 / 18$ & 22,2 \\
\hline & Lazer & $3 / 18$ & 16,8 \\
\hline & Apenas ração comercial & $0 / 18$ & 0,0 \\
\hline & Apenas resto de comida & $2 / 18$ & 11,1 \\
\hline & Apenas milho & $4 / 18$ & 22,2 \\
\hline & $\begin{array}{l}\text { Resto de comida mais milho ou } \\
\text { ração comercial }\end{array}$ & $12 / 18$ & 66,7 \\
\hline \multirow{2}{*}{ Contato com aves silvestres $* * *$} & $\operatorname{Sim}$ & $13 / 18$ & 72,2 \\
\hline & Não & $5 / 18$ & 27,7 \\
\hline \multirow{2}{*}{$\begin{array}{l}\text { Presença de roedores ou fezes } \\
\text { de roedores }\end{array}$} & Sim & $9 / 18$ & 50 \\
\hline & Não & $9 / 18$ & 50 \\
\hline \multirow{2}{*}{$\begin{array}{l}\text { Assistência por médicos } \\
\text { veterinários }\end{array}$} & Sim & $2 / 18$ & 11,1 \\
\hline & Não & $16 / 18$ & 88,8 \\
\hline
\end{tabular}

* Vacinas contra Marek e Doença de Newcastle

** Utilização apenas quando algum problema no plantel era detectado

*** Contato com passeriformes durante a oferta de alimentação, geralmente milho, ou que também utilizavam dos bebedouros.

Fonte: Elaboração dos autores.

\section{Pesquisa microbiológica em ovos de feiras livres}

Os resultados bacteriológicos dos ovos coletados em feiras livres demonstraram que $46,7 \%$ das amostras da casca foram positivas para alguma espécie de enterobactérias, enquanto que o percentual obtido para as amostras do conteúdo interno foi de $33,3 \%$. Nas cascas dos ovos analisados foram isolados: Escherichia coli (13,3\%), Citrobacter spp. (10,0\%), Enterobacter spp.(6,7\%), Proteus spp. (6,7\%), Providencia spp. (3,3\%), Klebsiella spp. (3,3\%), Shigella spp. (3,3\%). No conteúdo interno, Escherichia coli (13,3\%), Shigella spp. (6,7\%), Citrobacter spp. (6,7\%), Yersinia spp. (3,3\%) e Klebsiella spp. (3,3\%), como mostra a tabela 3 . 
Tabela 3. Resultados bacteriológicos dos contaminantes das cascas e do conteúdo interno dos ovos das galinhas de fundo de quintal de Fortaleza.

\begin{tabular}{ccccc}
\hline \multirow{2}{*}{ Bactérias } & \multicolumn{2}{c}{ Micro-organismo contaminante da casca } & \multicolumn{2}{c}{$\begin{array}{c}\text { Micro-organismo contaminante do } \\
\text { conteúdo interno }\end{array}$} \\
\hline Escherichia coli & n/N (\%) & Regional & n/N $(\%)$ & Regional \\
Citrobacter & $3 / 30(13,3 \%)$ & I, II, III, VI & $4 / 30(13,3 \%)$ & I,II,III,IV \\
Enterobacter spp. & $2 / 30(10,0 \%)$ & I,II,IV & $2 / 30(6,7 \%)$ & II,IV \\
Proteus spp. & $2 / 30(6,7 \%)$ & I,IV & $0 / 30(0,0 \%)$ & - \\
Providencia spp. & $1 / 30(3,3 \%)$ & II,VI & $0 / 30(0,0 \%)$ & - \\
Klebsiella spp. & $1 / 30(3,3 \%)$ & III & $0 / 30(0,0 \%)$ & - \\
Shigella spp. & $1 / 30(3,3 \%)$ & III & $1 / 30(3,3 \%)$ & VI \\
Yersinia spp. & $0 / 30(0,0 \%)$ & V & $2 / 30(6,7 \%)$ & II,V \\
\hline Total & $14 / 30(46,7 \%)$ & - & $1 / 30(3,3 \%)$ & III \\
\hline
\end{tabular}

Fonte: Elaboração dos autores.

\section{Discussão}

Assim como ocorreu nesta pesquisa, relatos científicos sobre soroprevalência de Salmonella spp. em GFQ a partir do teste SAR mostram que a positividade é frequentemente detectada. Maia et al. (2011) pesquisaram 489 amostras de soro sanguíneo de aves de fundo de quintal de propriedades rurais localizadas no município de Feira de Santana (BA), localizadas próximos a matrizeiros, e verificaram que 5,32\% apresentaram reação sorológica positiva para Salmonella Gallinarum e Salmonella Pullorum, sendo que $36,36 \%$ eram afetadas. Buchala et al. (2006) analisaram amostras de sangue de aves de subsistência criadas próximos a matrizeiros localizados no Estado de São Paulo e observaram que $16,5 \%$ das galinhas apresentaram reação positiva para Salmonella Pullorum.

Apesar do relevante percentual de aves positivas para Salmonella spp. detectado a partir do exame de SAR, o teste microbiológico indicou negatividade para todas as amostras de swabs cloacais avaliadas. Esse resultado assemelha-se ao que foi observado por Gambiragi et al. (2003) que analisou amostras de pintos de corte provenientes de três empresas localizadas na Região Metropolitana de Fortaleza (CE), pois ao analisar 300 amostras sanguíneas confirmaram que $33,3 \%$ das aves eram positivas a partir do teste de SAR, entretanto os microbiológico convencional revelaram que todas as amostras eram negativas. O teste de soroaglutinação rápida em placas pode apresentar resultados falsopositivos, devido sua baixa especificidade e baixa sensibilidade (GAST; BEARD, 1990), isso se explica pela possibilidade de ocorrerem reações cruzadas que podem ser encontradas em aves infectadas por E.coli, Enterobacter spp., Proteus spp. e Lactobacillus, que compartilham antígenos com Salmonella spp. (BERGQVIST; ROSENDE; BAUER, 1973).

A negatividade detectada nos exames microbiológicos de material coletado das galinhas pesquisadas também se assemelhou aos resultados obtidos por Guimarães (2006) no qual pesquisou a prevalência de salmonelas em 300 aves (Gallus gallus) adultas criadas em propriedades não tecnificadas do Distrito Federal. Ela concluiu que essa ausência deve estar associada à ausência da bactéria no ambiente em que as aves amostradas vivem ou a maior resistência dessas aves à infecção por salmonelas.

Alguns dos itens respondidos no questionário realizados entre os proprietários podem explicar a ausência da Salmonella spp. nas amostras observadas. Uma pequena parcela das propriedades 
$(5,5 \%)$ criavam suas aves em regime intensivo. De acordo com Berchieri e Macari (2000) a introdução, instalação, permanência e disseminação da Salmonella spp. são favorecidas pelo sistema intensivo na avicultura industrial. Outro fator que possa ter influenciado a negatividade encontrada foi a troca de água e limpeza dos bebedouros realizada diariamente pela maioria das propriedades. Apesar de não se ter buscado compreender a forma específica de como a limpeza e desinfecção dos bebedouros era realizada, a substituição de água diariamente pode ter evitado a proliferação de micro-organismos trazidos por aves silvestres que utilizavam da água para a dessedentação. Segundo Gama et al. (2008), as bactérias contaminam a água principalmente através das fezes, material de expectoração e muco de animais domésticos e silvestre.

Em relação à taxa de contaminação microbiana de enterobactérias na casca e conteúdo interno de ovos de GFQ em pontos de venda em feiras livres de Fortaleza, evidenciou-se uma condição de deficiência higiênico-sanitária às quais o produto era submetido. Na literatura científica são poucos os trabalhos que trazem dados relacionados à prevalência de enterobactérias em ovos de galinha comercial e principalmente em aves de fundo de quintal, o que dificultou a comparação dos resultados. Entretanto a pesquisa de Musgrove et al. (2008) mostrou que a prevalência microbiana na casca dos ovos disponibilizado aos consumidores pode ser bem menor. Os pesquisadores esclarecem que nos Estados Unidos a lavagem dos ovos antes da venda é prática obrigatória e verificou que os ovos antes desse procedimento sanitário possuem carga de até $83,2 \%$ de Enterobacteriaceae e outros micro-organismos, enquanto que após a lavagem essa taxa de contaminação pode diminuir para até $5,1 \%$. Desta forma, verifica-se de acordo com Musgrove et al. (2004) que nas cascas dos ovos podem ser encontrados diversos micro-organismos , e assim servir como veículo de transmissão de importantes patógenos aos seres humanos (FAVIER et al., 2000).
Em relação à taxa de contaminação do conteúdo interno, Andrade et al. (2004) observaram que $58,18 \%$ dos ovos comercializados em feiras livres de Goiânia (GO) eram positivos, entretanto apenas $12,9 \%$ estavam contaminados por bactérias da família Enterobacteriaceae. Dessa maneira, o percentual de positividade detectada nas amostras de ovos vendidos em Fortaleza (33,3\%) pode ser considerado preocupante, pois alguns desses microorganismos podem causar toxi-infeção alimentar aos consumidores (STEPIEN-PYSNIAK, 2010).

A espécie de micro-organismo mais isolados na casca dos ovos e conteúdo interno foi a Escherichia coli $(13,3 \%)$. A importância desse registro devese ao fato de que as galinhas são susceptíveis à colonização por E.coli O157: H7, um importante patógeno para seres humanos (GAMA et al., 2008), e assim como outros agentes infecciosos podem ser transferidos aos ovos imediatamente após a oviposição (COPUR et al., 2010). Entretanto, normalmente a contaminação dos ovos ocorre após a postura, e a maioria dos ovos contém pouca ou nenhuma bactéria (MAYES; TAKEBALLI, 1983).

Musgrove et al. (2008) também observaram que E. coli, assim como Enterobacter, foram os patógenos mais prevalentes em amostras de cascas dos ovos desinfetados e destinado ao comércio. Em relação ao conteúdo interno de ovos de feiras livres, Andrade et al. (2004) observaram que $E$. coli e Citrobacter spp., estavam presentes em apenas $1,85 \%$ das amostras analisadas, sendo menos isoladas apenas em relação à Pseudomonas (2,94\%) e Enterobacter (5,51\%). Adesiyun et al. (2006) observaram que Klebsiella spp. (12,9\%), seguido por Pseudomonas (9,7\%) foram os microorganismos mais isolados de conteúdo internos de ovos vendidos em centro comerciais de Trinidad.

\section{Conclusão}

Não houve isolamento de Salmonella spp. em nenhuma das amostras de ração, swabs cloacais e de arrasto, nem de cascas e conteúdo interno dos ovos 
coletados nas propriedades de galinhas de fundo de quintal de Fortaleza, Ceará.

Devido o razoável percentual de enterobactérias detectados em ovos adquiridos em feiras livres, os resultados obtidos nesta pesquisa podem servir como alerta sanitário, pois ficou evidente o comprometimento do conteúdo interno, o que deixa o produto impróprio para alimentação, podendo trazer sérios riscos a saúde do consumidor.

\section{Agradecimentos}

Os autores agradecem à Coordenação de Aperfeiçoamento de Pessoal de Nível Superior (CAPES) pelo apoio essencial proporcionado para o desenvolvimento desse trabalho e ao Laboratório de Estudos Ornitológicos - LABEO/FAVET/UECE.

Esse artigo foi aprovado pelo Comitê de Ética para uso de Animais/Universidade Estadual do Ceará (CEUA) pelo seguinte número de protocolo: $\mathrm{N}^{\circ} 11584764-2$.

\section{Referências}

ADESIYUN, A.; OFFIAH, N.; SEEPERSADSINGH, N.; RODRIGO, S.; LASHLEY, V.; MUSAI, L. Frequency and antimicrobial resistance of enteric bacteria with spoilage potential isolated from table eggs. Food Research International, Toronto, v. 39, n. 2, p 212219, 2006.

ALCOCER, I. R. Sorotipagem, fagotipagem, caracterização molecular de cepas de salmonella spp. e avaliação epidemiológica de surtos ocorridos no paraná de 1999 a 2004. 2004. Tese (Doutorado em Veterinária) Universidade Estadual de Londrina, Londrina.

ANDRADE, M. A.; CAFÉ, M. B.; DE SÁ JAYME, V.; ROCHA, P. T.; LEANDRO, N. S. M.; STRINGHINI, J. H. Avaliação da qualidade bacteriológica de ovos de galinha comercializados em Goiânia, Goiás, Brasil. Ciência Animal Brasileira, Goiânia, v. 5, n. 4, p. 221228, 2004.

BERCHIERI JUNIOR, A.; MACARI, M. Salmoneloses aviárias. In: FACTA. Doença das aves. Campinas: 2000. cap. 4.1, p. 185-194.
BERGQVIST, E.; ROSENDE, S.; BAUER, R. Factores que puedem alterar uma prueba de hemoaglutinacion en el diagnostico de Pullorosis. Agricultura Técnica, Santiago, v. 33, n. 4, p. 204-208, 1973.

BRASIL. Ministério da Agricultura - Portaria SDA. N. 126, de 06 de novembro de 1995. Normas para diagnóstico das Salmoneloses aviárias, Diário Oficial [da] União, Brasília, DF, 06 nov. 1995. Seção 1, p. 17694.

Instituto Brasileiro de Geografia e Estatística. Sistema de recuperação automática. Rio de Janeiro, 2005. Disponível em: <http://www.sidra.ibge.gov.br $>$. Acesso em: 05 set. 2012.

BUCHALA, F. G.; ISHIZUKA, M. M.; MATHIAS, L. A.; BERCHIERI JÚNIOR, A.; CASTRO, A. G. M.; CARDOSO, A. L. S. P.; TESSARI, E. N. C.; KANASHIRO, A. M. I. Detecção de resposta sorológica contra Mycoplasma em aves de criatórios de "fundo de quintal" próximos a explorações comerciais do Estado de São Paulo. Arquivos do Instituto Biológico, São Paulo, v. 73, n. 2 p. 143-148, 2006.

CARDOSO, A. L. S. P.; TESSARI, E. N. C. Salmonella na segurança de alimentos. Arquivo do Instituto Biológico, Descalvado, v. 70, n. 1, p. 11-13, 2008.

COPUR, G.; ARSLAN, M.; DURU, M.; BAYLAN, M.; CANOGULLARI, S.; AKSAN, E. Use of oregano (Origanum onites L.) essential oil as hatching egg disinfectant. African Journal of Biotechnology, South África, v. 9, n. 17, p. 2531-2538, 2010.

FAVIER, G. I.; ESCUDIERO, M. E.; VELÁZQUEZ, L.; GUZMAN, A. M. S. Reduction of yersinia enterocolitica and mesophilic aerobic bacteria in egg-shell by washing with surfactants and their effect on the shell microstructure. Food Microbiology, London, v. 17, n. 1, p. 73-81, 2000.

FREITAS NETO, O. C.; PENHA FILHO, R. A. C.; BARROW, P.; BERCHIERI JÚNIOR, A. Sources of humannon-typhoid salmonellosis: a review. Brazilian Journal of Poultry Science, Campinas, v. 12, n. 1, p. 0111, 2010.

GAMA, N. M. S. Q.; C. K.; FERREIRA, N. T.; BUIM, M. R.; GUASTALLI, E. L.; FIAGÁ, D. A. M. Conhecendo a água utilizada para as aves de produção. Instituto Biológico, São Paulo, v. 70, n. 1, p. 43-49. 2008.

GAMBIRAGI, A. P. O. M.; SALLES, R. P. R.; AGUIAR FILHO, J. L.; CARDOSO, W. M.; OLIVEIRA, W. F.; ROMÃO, J. M.; TEIXEIRA, R. S. C. Salmonella sp. em frangos de corte de um dia de idade na região metropolitana de Fortaleza, CE. Acta Scientiae Veterinariae, Porto Alegre, v. 31, n. 2, p. 149-153, 2003. 
GAST, R. K.; SHIVAPRASAD, H. L.; BARROW, P. A. Salmonella Infections. In: SAIF YM, F. A. M.; GLISSON, J. R.; MCDOUGALD, L. R.; NOLAN, L. K.; SWAYNE, B. B. Diseases of poultry. 12. ed. Athens, Georgia: Blackwell Publishing, 2008. p. 619-674.

GAST, R. K.; BEARD, C. W. Production of Salmonella Enteritidis contaminated eggs by experimentally infected hens. Avian Diseases, Arizona, v. 34, n. 2, p. 438-446, 1990.

GUIMARÃES, H. K. Análise de prevalência de salmonelose em criações não tecnificadas de Gallus gallus no Distrito Federal. 2006. Dissertação (Mestrado em Veterinária) - Faculdade de Agronomia e Medicina Veterinária. Universidade de Brasília, Brasília.

LOURENÇO, M. C. S.; REIS, E. F. M.; VALLS, R. Salmonella entérica subsp houtenae sorogrupo O: 16 em um paciente HIV positivo: relato de caso. Revista Instituto de Medicina Tropical de São Paulo, São Paulo, v. 46, n. 3, p. 169-170, 2004.

MAIA, T. A. C.; RIBAS, J. R. L.; MOURA. L. G.; BATISTA, M. B.; GARRIDO, I.; SANTOS, J. C. M. Aves de quintal reagentes a Salmonella criadas entorno de matrizeiros no pólo avícola de Feira de Santana, Bahia. In: CONGRESSO BRASILEIRO DE MEDICINA VETERINÁRIA, 38., 2011, Florianópolis. Anais.... Florianópolis: Sociedade Brasileira de Medicina Veterinária, 2011. p. 1-3.

MAYES, F. J.; TAKEBALLI, M. A. Microbial contamination of the hen's egg: a review. Journal of Food Protection, Iowa, v. 46, n. 12, p. 1092-1098, 1983.

MUSGROVE, M. T.; JONES, D. R.; NORTHCUTT, J. K.; COX, N. A.; HARRISON, M. A. Identification of Enterobacteriaceae from washed and unwashed commercial shell eggs. Journal Food Protection, Iowa, v. 67, n. 11, p. 2801-2804, 2004.
MUSGROVE, M. T.; NORTHCUTT, J. K.; JONES, D. R., COX, N. A.; HARRISON, M. A. Enterobacteriaceae and related organisms isolated from shell eggs collected during commercial processing. Poultry Science, Champaign, v. 87, n. 6, p1211-1218, 2008.

PREFEITURA MUNICIPAL DE FORTALEZA. Regionais de Fortaleza. [S.1.: s.n], 2012. Disponível em: $<$ http://www.fortaleza.ce.gov.br>. Acesso em: 01 fev. 2012.

QUINN, P. J.; CARTIER, M. E.; MARKEY, B. Pseudomonas species. In: Clinical veterinary microbiology. London: Wolfe, 1994. p. 237-242.

SILVA, E. N. Medidas gerais de controle de salmonelas em frangos. In: CONFERÊNCIA APINCO DE CIÊNCIA E TECNOLOGIA AVÍCOLAS, 2005, Campinas. Anais... Campinas: FACTA, 2005. p. 229-237.

STEPIEN-PYSNIAK, D. Occurrence of gram-negative bacteria in hens' eggs depending on their source and storage conditions. Polish Journal of Veterinary Sciences, Olsztyn-Kortowo, v. 13, n. 3, p. 507-513. 2010.

THRUSFIELD, M. V. Epidemiologia veterinária. 2. ed. São Paulo: Roca, 2004.

WHITE, P. L.; SCHLOSSER, W.; BENSON, C. E.; MADDOX, C.; HOGUE, A. Environmental survey by manure drag sampling for Salmonella enteritidis in chicken layer houses. Journal of Food Protection, Iowa, v. 60, n. 10, p. 1189-1193, 1997.

WIGLEY, P.; BERCHIERI JUNIOR, A.; PAGE, K. L.; SMITH, A. L.; BARROW, P. A. Salmonella enterica serovar pullorum persists in splenic macrophages and in the reproductive tract during persistent, disease-free carriage in chickens. Infection and Immunity, Washington, v. 69 , n. 12, p. 7873-7879, 2001. 